\title{
Spiritual Intelligence: At a Glance!
}

\author{
Ms. Hema $G^{1 *}$, Dr. Vinita Advani ${ }^{2}$
}

\section{ABSTRACT}

Today's adolescents are getting very much affected and exposed to the changing society due to which they are facing much higher levels of stress. One of the many challenges faced by adolescents is academic performance. The adolescence period is the best time to develop positive emotions and training skills, because adolescents are seeking to find their identity and their future personality at this period. The ultimate goal of Education is all round development/holistic development of the student. All round development refers to physical fitness, mentally balanced, emotionally strong, socially adjusted and spiritually uplifted. WHO defines Health as 'physical, social, mental and Spiritual well being'. Thus, spiritual intelligence is closely related to Education and foundation of Education. The core values of spiritual intelligence which can find natural expression in curriculum includes connectedness, compassion, honesty, responsibility, respect, unity, service. This paper has reviewed the articles about spiritual intelligence, its dimensions, and its related concepts. Spiritual intelligence has a significant role in the quality of life. This paper has tried to put forth the concept of spirituality and spiritual Intelligence/Quotient, its theoretical and scientific background, principles and skills. It can be viewed as a form of intelligence. Spiritual intelligence predicts functioning and adaptation and offers capabilities that enable people to solve problems and attain goals. Understanding spirituality as a kind of intelligence, the psychological conception of spirituality is associated with the rational cognitive processes like goal achievement and problem solving. Thus, this paper is significant to Education field where spiritual intelligence can be introduced to the students through the curriculum which teaches students how to behave with others, how to make decisions and act in everyday stressful world of interacting with difficult people and situations.

Keywords: Spirituality, Spiritual Intelligence (SI), God Quotient (GQ), Spiritual Psychology

In the $21^{\text {st }}$ century there are three main outbursts. They are population explosion, knowledge explosion and explosion of aspirations. Due to such outbursts, it has become very difficult for us to exist and live our life successfully (Mishra and Vashist, 2014). Today's adolescents are getting very much affected and exposed to the changing society and are facing much higher levels of stress. One of the many challenges faced by adolescents is academic performance. The adolescence is known to have its own unique set of problems during which high levels of stress

\footnotetext{
${ }^{1}$ Lecturer, Department of Education, Kadi Sarva Vishwavidyalaya, Gandhinagar, Gujarat

${ }^{2}$ Assistant Professor, Department of Education, Kadi Sarva Vishwavidyalaya, Gandhinagar, Gujarat *Corresponding Author

(C) 2015 I Hema G, V Advani; licensee IJIP. This is an Open Access Research distributed under the terms of the Creative Commons Attribution License (http://creativecommons.org/licenses/by/2.0), which permits unrestricted use, distribution, and reproduction in any Medium, provided the original work is properly cited.
} 
gets manifested to form emotional imbalance, tensions, suicide, rebelliousness, destructiveness, non-uniformity and disobedience, aggressive and attention deficit.

According to National Survey of Child and Adolescent well being (NSCAW) 1997-2013, adolescences well-being depends on the capacity of their family to nurture and care for them. The vast majority (86\%) of adolescent who have received a report of child abuse or neglected remain in home following a maltreatment investigation. This survey is showing the real picture of adolescent stress and their well-being. Physical changes and development in an adolescent are closely related with emotional, mental and social development. Adolescence is also the stage when young people extend their relationships beyond parents and family and are intensely influenced by their peers and the outside world in general. If intellectual, emotional and spiritual intelligence level is high in adolescents they will able to deal positively with all the aspects of stress and matters related to physical psychological and emotional well. This is also a follow up of the National policy of Education and NCERT's National Curriculum framework (NCF) 2005 to guide the school's curriculum across the country which recognized adolescence education as an impotent area in school education (Mishra and Vashist, 2014).

\section{Spiritual Intelligence and Education}

The ultimate goal of Education is all round development/holistic development of the student. All round development refers to physical fitness, mentally balanced, emotionally strong, socially adjusted and spiritually uplifted. WHO (World Health organization) defines Health as 'physical, social, mental and Spiritual well being'. Thus, spiritual intelligence is closely related to Education and foundation of Education. The core values of spiritual intelligence which can find natural expression in curriculum includes connectedness, compassion, honesty, responsibility, respect, unity, service. Today's Education is the industrial unit of clerk. Our Teachers, Engineers, Doctors are the experts but they don't have ethical, social, and broad view. We live a very mechanical life. But, nothing is unconscious in the world. Therefore, Education must have the foundation of spirituality. Today's life has become more complicated one. The competitive mind of man is inquisitive but man has lost his direction. So life has become directionless \& unstable. Man has forgotten self, also forgotten awareness about world \& he has lost his place in this world. Who am I? Why am I here? While searching answers to these questions self-awareness is becoming critical. Self awareness is understood through spiritual intelligence by meditation and self discipline (Bhangale and Mahajan, 2013).

Present educational system has literally failed to develop life skills which are essential for future of the student. Overburdened curriculum corporate educational system, great expectations of the teachers and parents is making the children more stress prone \& leading to more psychological problems, insecurity negative competitions, developing suicidal tendencies among the school and college students. Spiritual growth is as much necessary for personality as air water \& food. It gives the right perspective. Spiritual intelligence is the best tool to achieve our goals (Bhangale and Mahajan, 2013). 


\section{Spirituality}

The quest for spirituality has taken many forms. According to Allport, (1950), spirituality may be understood as actions in service of a perceived ultimate being and a belief of the permanence of all beings. Recent studies have defined spirituality as living meaningfully with an ultimate being (Bregman \& Thierman, 1995), an existing vital force (Rayburn \& Rayburn, 1996) or the ultimate truth (Wong, 1998). Other studies have defined spirituality as the feeling of being connected to oneself, to others and to the universe (Mitroff \& Denton, 1999) or as an individual's relationship with a higher being (Benefiel, 2005).

As referred by Evren and Fatih (2011), spirituality is the search for an ultimate being, and it is the passion that a person has for an ultimate being. Spirituality is highly individual and intensely personal. It is the basic belief that there is a 'supreme power', a force or energy. We can name it as the thing which governs the entire universe. The word 'spirit' has been derived from the Latin word, 'spiritus', which means "breath". The term 'spirituality' covers a broad spectrum of meanings and many definitions. It also has interrelationship with other psychological constructs. All the meanings are relating to a non-corporal substance contrasted with the material body. The spirit of a human being is the animating, sensitive or vital principle in that individual, (similar to the soul, 'aatma'), taken to be the seat of the mental, intellectual and emotional powers. Spirituality is the belief in ultimate goodness and righteousness.

Danesh (1997) in his book "The psychology of spirituality" opines that the ultimate human reality is a spiritual one. He stated that there is a purpose for everything and everyone. It is inextricably connected with caring, hope, kindness, love and optimism. Spirituality gives one the power and the will to persist in the face of seemingly hopeless and insurmountable odds. It provides the strength to carry on the good fight for righteous cause. It provides an abiding sense of hope and optimism in hopeless situation. Personal integrity while facing distress and complex situations is an indication of spirituality. So, spirituality is a type of anchoring into the domains of the Almighty in the complex chaotic worldly voyage. This recognizes the interconnectedness of human soul to the supreme soul.

The main objective of this paper is to explore the concept of Spirituality, Spiritual Intelligence and its connection with education.

\section{Need of Spiritual Quotient}

In the present period of life, stress is a psychological agent that influences physical and emotional well-being of adolescents. Adolescents can improve their sense of well-being related to stress by engaging in health promotion activities (Mishra and Vashist, 2014). The much spoken concepts these days in psychology are Intelligence Quotient (IQ), Emotional Quotient (EQ) and Spiritual Quotient (SQ). As referred by Mishra and Vashist (2014), Nathawat (2001) defined "a close inspection of these concepts will suggest us that IQ is important for entrance in educational institutions, EQ is essential for success in life and SQ is useful for meaningful life." 
George and Shari (2014), found that low emotional intelligent group was high in stress and high emotional intelligent group had low stress.

Zohar and Berman (2001) presented a conceptual comparison of the three areas of intelligence. Spiritual intelligence is about creative, rule-making, rule-breaking and insightful transformative thinking unlike cognitive or logical intelligence (IQ) which is about the rational, logical and rule-bound thinking, and emotional intelligence (EQ), which is about associative, habit bound, pattern-recognizing and emotive thinking. Spiritual Intelligence often manifests in a spiritual pathway that involves duty, understanding, and transformation of inner sight, nurturing and brotherhood. Spiritual intelligence is the most important attribute of human beings while IQ and EQ are viewed as integral part of SQ which was also agreed by western authors like Danah Zohar and Ian Marshall. The scientific and neuropsychological evidence for SQ has been put forth by identifying a God-spot or a God quotient (GQ) in the human brain (Mishra and Vashist, 2014).

SQ allows the intrapersonal and the interpersonal emotions to fill the gap between self and the other. Goleman (1995) wrote about interpersonal, or within-the-self, emotions and interpersonal emotions- those we share with others or use to relate to others. However, EQ alone cannot help us bridge the gap. It needs SQ to have knowledge about what we are and what things mean to us, and how things give others and their meanings a place in our own world.

Spiritual intelligence also plays a very important role in practical life. Each area of life contains a set of relationships. Both success in life and levels of satisfaction in each area of life depends on how well one is able to interact within those relationships.

The best predictors of high SQ are happiness, serenity, good self-esteem and harmonious \& loving relationships. Ability to think out of box, modesty, and an access to energies beyond ego and beyond day-to-day concerns are the signs of high SQ. Spiritual intelligence is the way we assign meaning and feel connected to the power of larger than ourselves. Spiritual intelligence is one of the several types of intelligence that can be developed independently and contributes to psychological well being and overall healthy human development (Vaughan, 2003). Spiritual intelligence is a set of adaptive mental capacities based on non-material and transcendent aspects of reality (Sood et al, 2012).

To solve the problems faced by adolescents, Spiritual Intelligence plays very important role. It is a necessary and important personal endowment which enables an individual to maintain both the inner and outer peace and shares love regardless of the good or bad circumstances. Therefore, spiritual intelligence can help in conflict management and peace co-existence in the society. Thus, we can understand that the need of Spiritual Intelligence or SQ which plays very important role in stress management, in the improvement of physical and psychological well-being and for successful life. 


\section{Definitions of Spiritual Intelligence:}

According to Zohar and Marshall (2000), spiritual intelligence refers to the development of our longing and capacity for meaning, vision and value which facilitates a link between reason and emotion, between mind and body. Spiritual intelligence also enables us to incorporate the interpersonal and intrapersonal qualities within self, and to transcend the gap between self and others. Spiritual intelligence is the set of abilities that individuals use to apply, manifest and embody spiritual resources, values and qualities in ways that enhances their daily functioning and well-being (Amram 2007). According to Emmons (2000), the adaptive use of spiritual information to facilitate everyday problem solving and goal attainment is known as spiritual intelligence.

Spiritual intelligence was further conceptualized by Wigglesworth (2006) as the ability to behave with compassion and wisdom while maintaining the inner and outer peace, regardless of the circumstances. According to Wigglesworth (2006) Spiritual intelligence is the ability of individuals to behave with wisdom and compassion while maintaining inner and outer peace, regardless of the situation.

A person may have high SQ but have no faith in his or her religion or belief, and inversely, others may have low SQ although very religious. Religion based on, particular set of custom, beliefs and values, and usually depends on culture, and upbringing (Zohar and Marshall, 2004). However, spiritual quotient is hereditary capacity of the human brain, based on structures in the brain that gives us basic ability to form meanings, values, and beliefs in the first place; it means that, spiritual intelligence is "the soul's intelligence."

According to Stephen Covey (2004), "Spiritual intelligence is the central and most fundamental of all the intelligences, because it becomes the sources of guidance for the others".

Spiritual intelligence as defined by Nasel (2004) is the capacity in bringing out one's spiritual gifts and resources for further recognition, search for meaning, and the resolution to certain existential, spiritual and practical matters. Basically, spiritual intelligence involves in opening our hearts and also cultivates our capacity to experience wonder, admiration and gratitude.

\section{Conceptualization of Spiritual Intelligence:}

Spirituality is a means of creative opening to all of us. It brings within us the quality of liveliness which sparks investigation, ideas, observations, insights, empathy, earnest endeavors, artistic nature, and joyfulness. Spirituality is a supportive thread that runs throughout our life, bringing hope, compassion, gratitude, peace, sense of purpose, meaningful day, and courage while reaching, beyond the immediate world of the visible and concrete. As cited by Kurkure and Wasaikar (2014), Spirituality drives us to search and stay true to the values not ruled by material success. In this paper, the reviewer tries to conceptualize Spiritual Intelligence based on different authors who worked on Spiritual Intelligence. 


\section{Concept of Spiritual Intelligence according to Zohar and Marshall (2000):}

The intelligence which is required when we begin to open up to our spirit's journey and to search for a greater understanding of life is Spiritual Intelligence. According to Zohar \& Marshall (2000), SI is described as "The intelligence with which we address and solve problems of meaning and value; the intelligence with which we can place our actions and our lives in a wider, richer, meaning giving context; the intelligence with which we can assess that, one course of action or one life-path is more meaningful than another”). Spiritual Intelligence is not necessarily related to any particular religion as such, however it seems to be very much related to 'Righteousness' which is the Indian concept of 'DHARMA'. This is evident by the statement given by Zohar \& Marshall, regarding the relation between religions and Spiritual Quotient (SQ): "We can use SQ to become more spiritually intelligent about religion. SQ takes us to the heart of things, to the unity behind difference, to the potential beyond any actual expression. SQ can put us in touch with the meaning and essential spirit behind all great religions. A person high in SQ might practice any religion, but without narrowness, exclusiveness, bigotry or prejudice. Equally a person high in SQ could have very spiritual qualities without being religious at all”.

Zohar and Marshall gave the following major concepts of Spiritual Intelligence in their work:

- Spiritual Intelligence is used to transform an individual life into a better status.

- Spiritual Intelligence is used when one need to be flexible, visionary or creatively spontaneous.

- Spiritual Intelligence acts as our conscience. It gives an insight of what life's struggles are about. It helps to solve existential problems.

- Spiritual Intelligence is used to understand the meaning and essential objective behind all great religions.

- Spiritually intelligent person will be able to integrate intrapersonal and interpersonal intelligences. With the help of Spiritual Intelligence, one can fight with the problems of good and bad, life and death and also solve the problems of self and others.

- Spiritual Intelligence helps an individual to go beyond the materialistic world, beyond his immediate ego or self to live a life with a deeper level of meaning and purpose.

\section{Concept of Spiritual Intelligence according to Bowell (2005):}

Richard A. Bowell (founder of Spiritual Intelligence Training), in his book titled "The 7 Steps of Spiritual Intelligence: The Practical Pursuit of Purpose, Success and Happiness” discussed about the improvement of the inner strength and spiritual intelligence of a person, and suggests to discover the "why" of what we do, rather than the "what" or "how". The seven steps of Spiritual Intelligence given by Bowell:

1. Awareness: The first step towards spiritual Intelligence is awareness. Sense organs play an important role in bringing about awareness. It promotes recognition, associations, memories, dialogues etc., The main aim of this step is to make one individual to become aware about what he has not yet seen or heard or noticed. In this step, spiritually intelligent person will refrain from the relaxed state and keep oneself awaken to great challenges and adventures of evolving life. 
2. Meaning: This step emphasizes on value judgments in one's life. It develops consciousness of the world and all that lives within it. The meaning of things cannot be assumed.

3. Evaluation: Evaluation should never be done from the identity level of 'self' alone. It is a process by which one understands her/his self and this is to understand the other person too.

4. Being centered: Being centered is to occupy a higher level of engagement altogether. This step makes an individual committed to the growth of 'self' as a meaningful life.

5. Vision: Seeing what others have not yet seen is a sign of visionary. One should have a vision that can see beyond the materialistic world. This step helps in developing consciousness about the situation.

6. Projection: Action is followed by projection. Projection begins in the settlement of 'self', and in the vision of great wealth that can be achieved, when one truly sees the truth of the situation.

7. Mission: This final step towards spiritual intelligence integrates one's self with the truth of the situation. Mission statement is an important aspect of the corporate identity and it inspires those who follow.

Thus, the journey towards the Spiritual Intelligence will start by exploring Awareness, Meaning, and Evaluation, and become centered in one's true 'self'; then project his/her intelligence outward, use vision to take an overview of the situation, act with accuracy and finally come to an understanding of personal mission.

\section{Concept of Spiritual Intelligence according to Husain (2005):}

Akbar Husain (2005), opined that Spirituality is a major divine force in all religions of the world, cultures and traditions. The functioning of spirituality in an individual will be known completely by understanding the triangle within the body, mind and soul. Husain explained the concept of spiritual personality as the role of "Self" in building a spiritual human being and the ways to develop spiritual powers.

He described the characteristics of a spiritual personality as:

A man with spiritual personality respond to life in a well organized manner has positive emotions, desires and ideas. He strives to find happiness through self-expression An individual's self-efficacy, self-awareness, self-esteem, self-regard, self-acceptance, self-mastery, selfdiscipline and self-control points out to his spiritual personality.

Following are the major perspectives that he has raised in his work on "Spiritual Psychology":

1. Religion is not necessarily required to be spiritual. It is a kind of offering to God. Honesty, humility, sweetness and charity are the measuring scales of spirituality.

2. For the development of spirituality, one has to practice love and selfless kindness. Giving something which greatly valued, can measure one's selfless love. Spiritual love can be 
observed by one's faith in God as well as to others. It is possible through 'sheer sympathy', 'fidelity', 'love', 'faith', 'trust' and 'revelation'.

3. Spiritual health can be maintained through a set of spiritual exercises and qualities. A person is said to possess spiritual health if he finds a balance between life values, goals, belief systems and their relationship with themselves and with others. Spiritually healthy people will be humble, grateful, happy and friendly.

4. Spiritual transformation is the transformation of an individual towards divine nature. It takes place in three steps. First, an individual accepts the fact that he is incapable of solving his own problems; then the individual feels guilty for the cause of the present situation and desires for a new way. In the final step, the individual surrenders himself to the supreme powers.

\section{Concept of Spiritual Intelligence by others:}

Royes (2005) and King (2008) have also contributed to the theory of spiritual intelligence.

Royes (2005) presented a theoretical framework titled "Spirit Wave", as a process of holistic education in his study on "Spirit wave: A model of holistic change" at the University of Toronto, Canada. In the 'Spirit Wave model' of holistic change, one is developing Self-knowledge so that s/he may interact with the world in selfless service to 'Self', which s/he is; in his model he stressed on "I am the driver of my self-development, meditation is the vehicle, spiritual intelligence is the pilot, Self-realization is the direction, the inner road is the path, total freedom is the destination, and arrival is characterized by the feeling of ecstasy, with the beginning and ending of this journey being in the present."

Another model for the enhancement of spiritual intelligence was proposed by King (2008) in the study "Rethinking claims of spiritual intelligence: A definition, model, and measure". He proposed a four-factor model of spiritual Intelligence; i.e., supportive evidences were identified for the capacities of critical existential thinking, personal meaning production, transcendental awareness, and conscious state expansion. He constructed a spiritual intelligence measure, 'SI Self-Report Inventory (SISRI-24)', which displayed an excellent internal reliability and good fit to the proposed four-factor model of Spiritual intelligence.

\section{Scientific background for Spiritual Intelligence:}

As reported by Selman et. al. (2005), the concept of spirituality is old as humankind. However, it has been a challenge for psychologists and medical sciences to prove it and to give meaning to it within the physiology of human being as a material body. By early 1990's, the first research was carried out by Michael Parasinger, a well known neuropsychologist and in 1997, V.S. Ramachandran, neurologist, and his team members at the University of California. With the help of latest medical technology, their study identified a particular special spot in the human brain. This spot was located among neural connections in the temporal lobes of the human brain. The research subjects were exposed to spiritual or religious topics, and the scans of this particular 
spot in their brain were taken with Positron Emission Tomography. On studying the scans, the researchers noted lighting up of the neural areas near to the particular spot at the time of exposure of spiritual topics. This spot was referred as 'God spot'. Thus, the scientific and neuropsychological evidence for spiritual intelligence has been put forth by identifying a Godspot or a God quotient (GQ) in the human brain. The necessary condition for spiritual intelligence is existence of 'God spot'. But for being spiritually intelligent, 'God spot' also is not sufficient. The special abilities inferred by God spot have to be integrated into our general emotions and potentials for a higher spiritual intelligence. A neural process in the brain, which is responsible for integrating and giving meaning to our experiences was identified by an Austrian neurologist Wolf Singer, in 1990. This process literally binds our experiences together. Zohar and Marshall (2000) used this as a hint and extensive reference from the research work of Terrance Deacon, 1997, a well known Harvard neurologist and biologist anthropologist, who did research on origin of human language for the evolution of symbolic imagination and its consequent role in brain and social evolution) to argue the reality of the third kind of intelligence following rational intelligence (IQ) and Emotional intelligence (EQ), that is Spiritual intelligence, which is integrating and ultimate to all other intelligences. The concept of Spiritual intelligence was put forward by Zohar and Marshall (2000), by bringing together the collective evidences from psychology, neurology, anthropology and cognitive science. This concept was introduced as an expansion of psychology as a science, and argued the need for a new psychological model of the human self and of human personality. By doing this, they carefully insisted that spiritual intelligence is not necessarily about being religious, rather it is an internal innate ability of the human brain and psyche. The main theories relevant to spiritual intelligence supports that this intelligence is required to solve problems of values and to assess one's life path. Based on evidences, spiritual intelligence of people can be measured at least to some extent, and enhanced with respect to the major dimensions.

\section{Dimensions of Spiritual intelligence (Srivastava and Misra, 2012):}

Dimensions of spiritual intelligence are:

1. Inner self

2. The Inter self

3. Bio storia

4. Life perspectives

5. Spiritual actualization

6. Value orientation.

According to these dimensions, following factors can be identified - Conviction, Self-Efficacy, Inner Harmony, Forgiveness, Achievement Orientation, Self Actualization, Self Realization, Humane, Just, Generous, Ethical, Privy, Compatible, Altruism, and Optimism.

\section{COMPONENTS OF SPIRITUAL INTELLIGENCE:}

There are five components identified in spiritual intelligence (Emmons, 2000, Srivastava and Misra, 2012) 
1. Transcendence: The capacity to transcend the physical and material. Going beyond the egoistic self into an interconnected wholeness. Nurturing relationships and community with acceptance, respect, empathy, compassion, loving-kindness and generosity. Utilize a system perspective seeing the wholeness, unity and the interconnection among the diversity and differentiation.

2. Consciousness: The ability to experience heightened states of consciousness. It refers to knowing self and living consciously with clear intention and mindful, embodied awareness and presence.

3. Meaning: The ability to purify everyday experience. Experiencing significance in daily activities through a sense of purpose and a call for service, including in the face of pain and suffering.

4. Grace: The ability to utilize spiritual resources to solve problems. Living in alignment with sacred (divine, a universal life force, nature) manifesting love for and trust in life. Love, reverence and cherishing of life based on gratitude, beauty, vitality and joy. And having an optimistic outlook based on faith or trust.

5. Truth: The capacity to be virtuous. Acceptance and forgive, embrace and love. Openness, open heart and mind, open curiosity.

Noble (2000) agreed with Emmons' (2000) and has identified spiritual intelligence as an innate human potential and added two other components:

1. The conscious recognition that physical reality is embedded within a larger, multidimensional reality with which people interact, consciously and unconsciously, on a moment to moment basis.

2. The conscious pursuit of psychological health, not only for themselves but also for the sake of the global community.

Spiritual intelligence is the set of abilities that individuals use to apply, manifest and embody spiritual resources, values and qualities in ways that enhances their daily functioning and well being (Amram, 2000). Wigglesworth (2002), analyzed the above five components and developed twenty one detailed skills of spiritual intelligence. 


\section{Skills of Spiritual Intelligence}

\begin{tabular}{|l|l|}
\hline S. No & Skills of Spiritual Intelligence \\
\hline \multicolumn{3}{|l|}{ Higher Self/Ego Self Awareness } \\
\hline 1 & Awareness of own Worldview \\
\hline 2 & Awareness of life purpose (mission) \\
\hline 3 & Awareness of values hierarchy \\
\hline 4 & Complexity of inner thought \\
\hline 5 & Awarness of Ego self / Higher Self \\
\hline Universal Awareness \\
\hline 6 & Awareness of interconnectedness of all life \\
\hline 7 & Awarness of worldviews of others \\
\hline 8 & Breadth of time / space perception \\
\hline 9 & Awareness of limitations / power of human perception \\
\hline 10 & Awareness of spiritual laws \\
\hline 11 & Experience of transcendent oneness \\
\hline Higher Self / Ego Self Mastery \\
\hline 12 & Commitment to spiritual growth \\
\hline 13 & Keeping higher self in charge \\
\hline 14 & Living your purpose and values \\
\hline 15 & Sustaining your faith \\
\hline 16 & Seeking guidance from Spirit \\
\hline Social Mastery / Spiritual Presence \\
\hline 17 & A wise and effective spiritual teacher/mentor \\
\hline 18 & A wise and effective change agent \\
\hline 19 & Makes compassionate and wise decisions \\
\hline 20 & A calming, healing presence \\
\hline 21 & Being aligned with the ebb and flow of life \\
\hline
\end{tabular}

\section{Principles of Spiritual Intelligence:}

Zohar (2000) defined 12 different principles underlying spiritual intelligence:

1. Self-Awareness: Knowing what I believe in and value, and what deeply motivates me.

2. Spontaneity: Living in and being responsive to the moment.

3. Being vision and value-led: Acting from principles and deep beliefs, and living accordingly.

4. Holism: Seeing larger patterns, relationships, and connections, having a sense of belonging.

5. Compassion: Having the quality of "feeling-with" and deep empathy.

6. Celebration of diversity: Valuing other people for their differences, not despite them.

7. Field independence: Standing against the crowd and having one's own convictions.

8. Humility: Having the sense of being a player in a larger drama, of one's true place in the world.

9. Tendency to ask fundamental "Why?" Questions: Needing to understand things and get to the bottom of them.

10. Ability to reframe: Standing back from a situation or problem and seeing the bigger picture or wider context. 
11. Positive use of Adversity: Learning and growing from mistakes, setbacks, and suffering.

12. Sense of vocation: Feeling called upon to serve, to give something back.

\section{LIMITATIONS OF THE PAPER}

The limitation of this conceptual paper is that, the authors explored the primary concepts of spiritual intelligence only from published scholarly articles. A dearth of further research is needed in this construct to enhance the student community.

\section{CONCLUSION}

Spiritual Quotient is a broad spectrum against which we assess the usefulness of an individual's life path or the need to change the particular direction of one's actions. Spiritual Intelligence is a distinct ability which is more than a cognitive ability. As per Zohar and Marshall (2000) assertion, SQ is the basis for emotional and rational intelligence. The concept of spiritual intelligence is a journey that may not be achieved all at once. It surpasses the conscious mind and goes beyond the ego. Constructs of spirituality and intelligence are merged by and a new construct is shaped as Spiritual Intelligence. Therefore, Spiritual Intelligence represents the ability for integrative perception that sees the whole beyond its parts. Psychological professionals have recognized the power of Spiritual Intelligence, which are known as the capacity to feel, understand and present the highest part of themselves, others and the world around. As a kind of intelligence, spiritual intelligence is an integrative conception like goal achievement and problem resolution. This sort of intelligence gives a general basis for the individual to be able to consider his search for goals and meaning in life, and to move in the direction of the aims of life.

The important key idea here is that individuals need to have a meaning and value in their life and work. Meaning and value depends on the beliefs and values that motivates and drives our behavior. So, the deepest level of intelligence is Spiritual Intelligence which has nothing to do with religion or any rigid belief system. SQ is a process of personal insight and experience, not a package of beliefs. Reviewing the concepts of spiritual intelligence, the author believes that this sort of intelligence can be improved with training. Adolescence is an important stage for spiritual intelligence training. In conclusion, we can say that studies mentioned so far indicate that, today the field of psychology has shown the tendency towards the spiritual dimensions and widen the horizon for extended research that can reflect the profound influence of spiritual forces on the human body and mind, and makes clear the importance of Spiritual Intelligence. Evidences of research and review of all concepts of Spiritual Intelligence show the effect of SI on fundamental improvements in health and well-being of human beings.

\section{REFERENCES}

Allport, G. W. (1950). The Individual And His Religion. New York: Macmillan

Amram, Yosi (2007). The Seven Dimensions of Spiritual Intelligence: An Ecumenical Grounded Theory. Paper Presented at the 115th Annual (August 2007) Conference of the American 
Psychological Association, San Francisco, CA. Summary available on http://www.yosiamram.net/papers/

Benefiel, M. (2005). The second half of the journey: Spiritual leadership for organizational transformation. The Leadership Quarterly, 16, 723-747.

Bhangale S.D and Mahajan S.R (2013), Spiritual Intelligence - Emerging Issue in Education, EDUBEAM Multidisciplinary- online research Journal, Vol-9(1), ISSN 2320 - 6314

Bowell, R.A,(2005). The Steps Of Spiritual Intelligence, Nicholes Brealey, UK.

Bregman, L., \& Thierman, S. (1995). First person mortal: Personal narratives of illness, dying, and grief. New York: Paragon.

Danesh, H. B. (1997). The psychology of spirituality. New Delhi: Sterling

Emmons A. R. (2000). Spirituality and Intelligence: Problems and Prospects. The International Journal for the psychology of religion, 10(1), 57-64

Evren A and Fatih S (2011), The Relationship between Spiritual Leadership and Issues of Spirituality and Religiosity: A Study of Top Turkish Managers. Istanbul, Turkey International Journal of Business and Management Vol. 6, No. 4; April 2011

George R and Shari B (2014), Causes of youth stress- an exploration, International Multidisciplinary e-Journal ISSN 2277 - 4262

Goleman, D. (1995). Emotional Intelligence. Bantnam, New York

Husain, Akbar, Dr. (2005). Spiritual intelligence scale.

Kurkure and Wasaikar (2014) Spiritual Intelligence as a tool to enhance personality in teacher trainees, International Multidisciplinary Research Journal, Vol-11(1), ISSN 2321-0397 Retrieved from http://www.emrj.net/Dr\%20P.N.Kur0\&\%20Prof.\%20Vinayak.\%20R.\%20Wasaikar.pdf on $23 / 10 / 2015$.

Mishra P and Vashist K (2014). A review study of Spiritual Intelligence, stress and well-being of adolescents in 21st century, International Journal of Research in Applied, Natural and Social Sciences ISSN(E): 2321-8851; ISSN(P): 2347-4580 Vol. 2, Issue 4, Apr 2014, 11-24 Rajasthan, India.

Mitroff, I. I., \& Denton, E. A. (1999). A spiritual audit of corporate America: A hard look at spirituality, religion, \& values in the workplace. San Francisco, CA: Jossey-Bass.

Nasel, Dagmar Dasha. (2004). Spiritual orientation in relation to spiritual intelligence: A new consideration of traditional Christianity and New Age/individualistic spirituality. Doctoral Dissertation, University of South Australia: Australia

Noble, E.P. (2000). The DRD2 gene in psychiatric and neurological disorders and its phenotypes. Pharmacogenomics, 1:309-333.

Rayburn, J. M., \& Rayburn, L. G. (1996). Relationship between Machiavellianism and type a personality and ethical-orientation. Journal of Business Ethics, 15, 1209-1220.

Selman V, Selman RC and Selman E (2005), Spiritual Intelligence/-Quotient, College Teaching Methods \& Styles Journal -Volume 1( 3) The American University, Washington, DC

Sood S, Bakhshi and Gupta R (2012), Relationship between personality traits, spiritual intelligence and well being in university students, Journal of Education and Practice Vol 2 (10). Retrieved from http://pakacademicsearch.com/pdf-files/edu/413/5559\%20Vol\%203,\%20No\%2010\%20(2012).pdf on 23/10/2015.

Srivastava A and Misra S (2012), Is Spriritual Quotient A Beter Tool Of Success: Spirituality In The New World Order, EXCEL International Journal of Multidisciplinary Management Studies Vol.2 Issue 1, ISSN 22498834 Online available at http://zenithresearch.org.in/ www.zenithresearch.org.in 
Vaughan, F. (2003): What is Spiritual Intelligence? Journal of Humanistic Psychology, Sage Publications. Vol. 42, No. 2. 16-33.

Wigglesworth, Cindy (August 2006) "Why Spiritual Intelligence is Essential to Mature Leadership", Integral Leadership Review Volume VI, No. 3.

Wong, P. T. P. (1998). Meaning-centered counseling. In P. T. P. Wong and P. S. Fry (Eds.), The human quest for meaning (pp. 395-435). Mahwah, NJ: Lawrence Erlbaum Associates, Inc.

Zohar and Marshall. (2000). SQ: Spiritual intelligence: The ultimate intelligence. London: Bloomsbury.

Zohar and Marshall. (2004). SQ: Spiritual intelligence: The ultimate intelligence. London: Bloomsbury.

Zohar D, Berman M 2001. Developing Spiritual intelligence through ELT. Paper presented at the Brighton IATEFI Conference. 